Review

\title{
The Puzzling Role of CXCR4 in Human Immunodefi- ciency Virus Infection
}

\author{
Elisa Vicenzi ${ }^{1}$, Pietro Liò ${ }^{2}$, and Guido Poli ${ }^{3,4} \bowtie$ \\ 1. Viral Pathogenes and Biosafety, San Raffaele Scientific Institute, Milano, Italy; \\ 2. Computer Laboratory, University of Cambridge, Cambridge, United Kingdom; \\ 3. AIDS Immunopathogenesis Units, San Raffaele Scientific Institute, Milano, Italy; \\ 4. Vita-Salute San Raffaele University, School of Medicine, Milano, Italy.
}

$\triangle$ Corresponding author: Prof. Guido Poli, P2/P3 Laboratories, DIBIT-1, Via Olgettina n. 58, 20132, Milano, Italy. Tel: +39-02-2643-4909; Fax: +39-02-2643-4905; poli.guido@hsr.it.

() Ivyspring International Publisher. This is an open-access article distributed under the terms of the Creative Commons License (http://creativecommons.org/ licenses/by-nc-nd/3.0/). Reproduction is permitted for personal, noncommercial use, provided that the article is in whole, unmodified, and properly cited.

Received: 2012.10.16; Accepted: 2012.12.26; Published: 2013.01.13

\begin{abstract}
The human immunodeficiency virus type-I (HIV-I) is the etiological agent of the acquired immunodeficiency syndrome (AIDS), a disease highly lethal in the absence of combination antiretroviral therapy. HIV infects $\mathrm{CD}^{+}$cells of the immune system (T cells, monocyte-macrophages and dendritic cells) via interaction with a universal primary receptor, the CD4 molecule, followed by a mandatory interaction with a second receptor (co-receptor) belonging to the chemokine receptor family. Apart from some rare cases, two chemokine receptors have been evolutionarily selected to accomplish this need for HIV-I: CCR5 and CXCR4. Yet, usage of these two receptors appears to be neither casual nor simply explained by their levels of cell surface expression. While CCR5 use is the universal rule at the start of every infection regardless of the transmission route (blood-related, sexual or mother to child), CXCR4 utilization emerges later in disease coinciding with the immunological deficient phase of infection. Moreover, in most instances CXCR4 use as viral entry co-receptor is associated with maintenance of CCR5 use. Since antiviral agents preventing CCR5 utilization by the virus are already in use, while others targeting either CCR5 or CXCR4 (or both) are under investigation, understanding the biological correlates of this "asymmetrical" utilization of HIV entry co-receptors bears relevance for the clinical choice of which therapeutics should be administered to infected individuals. We will here summarize the basic knowledge and the hypotheses underlying the puzzling and yet unequivocal role of CXCR4 in HIV-I infection.
\end{abstract}

Key words: HIV, chemokine receptor, CCR5, CXCR4, CD4, integrin, AMD3100.

\section{HIV entry into $\mathrm{CD}^{+}$cells of the immune system}

In spite of the successful advent of combination antiretroviral therapy (cART) HIV infection still spreads throughout the world still waiting for a preventative vaccine. In the absence of cART, after an initial phase of symptomatic infection, known as acute retroviral syndrome and associated with constitutional symptoms and painful lymphadenopathy, the clinical conditions return to normality for years (in most patients) before reemerging in coincidence with the pre-terminal phase defined as acquired immunodeficiency syndrome (AIDS). During this time, the virus has eroded the host immune defenses and had plenty of opportunities to be transmitted to other individuals either by blood or blood products (as in intravenous drug users sharing needles and syringes), via homo- or hetero-sexual exchanges or from mother to child (either intra-uterus, at delivery or by breast feeding). Unfortunately, 30 years after the discovery of HIV as the etiological agent of AIDS [1,2] there are 
still millions of individuals not receiving cART and in whom the natural history of HIV disease repeats itself monotonously. In fact, it has been recently calculated that for every new person starting on cART other two becomes newly infected [3], thus highlighting that the virus is still winning the "arm wrestling" with the mankind.

In order to infect a new host, HIV needs to interact with two receptors (CD4 and CCR5 or CXCR4) expressed on the surface of its target cells, namely $\mathrm{CD}^{+} \mathrm{T}$ lymphocytes, monocyte-macrophages and dendritic cells (DC). However, access to these receptor can be facilitated or hampered by other cell surface molecules, the two most prominent of which are the integrin $\alpha 4 \beta 7$ and the molecule known as CD209/DC-SIGN (Dendritic Cell-Specific Intercellular adhesion molecule-3-Grabbing Non-integrin). The role of $\alpha 4 \beta 7$ in HIV-1 infection has been reviewed elsewhere [4]. However, it should be reminded that such a molecule protrudes from the cell surface more than the CD4 molecule and, therefore, it is highly likely that it engages in a first contact with the trimeric HIV gp120 envelope (Env). gp120 Env binding to $\alpha 4 \beta 7$ does not represent an absolute requirement for the infection, but it facilitates the interaction with CD4 and delivers a positive signal for HIV-1 spreading involving another integrin, CD11a/CD18 (also known as leukocyte functional antigen 1, LFA-1) which favors the fusogenic process mediated by gp41 Env via interaction with intercellular adhesion molecules (ICAM-1, -2 and -3) [5].

DC-SIGN has been originally described in myeloid $\mathrm{DC}(\mathrm{mDC})$ as a capture receptor that, although not leading to infection of DC (that become infected via the CD4/CCR5 route a $\mathrm{T}$ cells and macrophages), can preserve the infectious virions during their travel to the regional lymph nodes [6, 7]. In the nodes, mDC activate the specific $\mathrm{CD}^{+} \mathrm{T}$ cells that become infected by a "kiss of death" delivered by the DC-SIGN associated virus. DC-SIGN expression has been later described in other cells such as macrophages $[8,9]$ where it likely plays a similar role [9]. Other molecules, such as CD206/mannose receptor have been also credited with similar functions in the context of HIV infection [10].

Independently of the facilitating role of other cell surface molecules, the crucial interaction of the virus with the cell involves the CD4 molecule, as known since 1984 [11]. Interaction of CD4 with gp120 Env leads to a conformational change of the viral molecule that exposes cryptic immunogenic regions required for interaction with the co-receptor and, particularly, with CCR5 (while those for CXCR4 are more exposed in the native gp120 Env) [4]. Engage- ment of the second receptor by gp120 Env induces a sharp conformational change in gp41 Env that, with a "jackknife-like movement" fuses the virion and target cell membranes therefore starting the infection process.

Once gained entry into the cells, the virion undergoes an "uncoating" phase after which a pre-integration complex of viral proteins (reverse transcriptase, RT, VpR and p17 Matrix) travel to the nuclear pore and then access to the cell nucleus. Here, the reverse transcription process is completed resulting in both circular and linear forms of double stranded DNA. Linear HIV DNA becomes part of the host genome as a "provirus" by means of the viral enzyme integrase. Cells carrying integrated proviruses are nowadays considered the main obstacle to viral eradication and the central limitation to otherwise effective cART in that its suspension leads to reactivation of HIV replication in $\mathrm{CD}^{+}$cells [12]. It should be underscored that the success of cART has been obtained by targeting the very enzymes responsible for these crucial steps of the virus life cycle (RT, integrase and protease, which processes the p55 Gag polyprotein in its mature products required for the assembly and release of new progeny virions). However, at least one category of antiviral agents (i.e., HIV entry inhibitors), in addition to the viral protein gp41 (T-20 and related peptides - [13]), targets host proteins involved in the different phases of virion attachment, including the CD4 molecule. However, the only agents currently approved for clinical use are inhibitors of CCR5 (Maraviroc and related compounds) although, historically, the first inhibitor of this class (AMD3100) was developed against CXCR4 [14].

\section{Discovery of CXCR4 and CCR5 as HIV co-receptors}

As mentioned, CD4 became soon recognized as the crucial entry receptor for HIV therefore accounting for a simple, but fundamentally correct immunopathogenetic view of HIV infection. The virus would infect and destroy $\mathrm{CD}^{+} \mathrm{T}$ lymphocytes (as observed in in vitro experiments with $\mathrm{CD}^{+}$cell lines or activated primary $\mathrm{T}$ cells) therefore causing a progressive state of immunodeficiency by eliminating "the orchestra director" of the immune system, as Anthony S. Fauci originally depicted it [15]. However, mice transgenic for human CD4 could efficiently bind the virus, but the infection would not proceed, indicating that at least another receptor(s) was required to bypass the cell membrane of $\mathrm{CD}^{+}$cells [16]. After several years of research and "false alarms", Edward Berger at the NIH named "Fusin" a previously iden- 
tified molecule that conferred fusogenic competence to cells expressing gp 120 Env on their surface [17]. However, only a fraction of gp120 Env molecules were Fusin-dependent, while others were not. Of interest, Fusin belonged to the 7 trans-membrane domain (7TM) family of receptors encompassing chemokine receptors. The same investigators together with several others achieved rapidly the solution: Fusin was actually CXCR4, the receptor for the chemokine named "Stromal cell derived factor-1 $\alpha$ (SDF-1 $\alpha$ )" now CXCL12 - named after the recognition of its fundamental role in the mobilization of stem cells from the bone marrow [18]. Expression of CXCR4 conferred fusogenic potential to those Env molecules expressed by so-called "Syncytium inducing (SI) strains" of HIV-1, earlier described by Dutch scientists $[19,20]$ as well as, in part, by Eva Maria Fenyo's laboratory [21], typically emerging in late phase disease and causing faster disease progression in comparison to non-SI (NSI) HIV-1 strains [22].

Another receptor accounted for the fusogenic potential of Fusin-independent HIV strains and, like Fusin, was a 7TM receptor belonging to the chemokine receptor family. This newly discovered receptor was CCR5 [23]. Of interest, a few months earlier than the discovery of "Fusin", the team of Paolo Lusso and Robert C. Gallo at the NIH reported the identification of three molecules (macrophage inflammatory protein
$1 \alpha$, MIP-1 $\alpha$, MIP-1 $\beta$, and a molecule known as "regulated upon activation normal $\mathrm{T}$ cell expressed and secreted, RANTES", now renamed CCL3, CCL4 and CCL5, respectively) as the key soluble inhibitors released by activated $\mathrm{CD} 8^{+} \mathrm{T}$ lymphocytes which could potently inhibit HIV replication in $\mathrm{CD}^{+} \mathrm{T}$ cells [24]. This phenomenon was originally described by Jay Levy (UCSF) and attributed to an unidentified "CD8 non-lytic antiviral factor (CAF)" causing transcriptional inhibition of HIV expression [25]. The three chemokines identified by Lusso and Gallo indeed inhibited HIV replication although with a different mechanism of what described for CAF. They were indeed the three ligands of a receptor yet to be discovered, i.e. CCR5, which prevented the infection of cells by "NSI strains" of HIV. Similarly, SDF-1 $\alpha / C X C L 12$ prevented the infection of "SI-viruses". Several other chemokine receptors have been later identified as potential entry co-receptors, including CCR2 and CCR3, but they usually play an ancillary role in association with CCR5. A partial exception is represented by CCR3 that may be of importance for the selection of neurotropic variants of HIV-1 and for the infection of brain microglial cells [26-28]. Based on the precise definition of the HIV entry process into $\mathrm{CD} 4^{+}$cells, a new classification of HIV phenotypes has been proposed and adopted (Table 1) [29].

Table I. Phenotypic classification of HIV-I based on co-receptor use.

\begin{tabular}{|c|c|c|c|}
\hline Chemokine Receptor & Natural Ligands & HIV-1 & Note \\
\hline CCR5 & CCL3, CCL4, CCL5 & R5 & Key viral phenotype for inter-individual transmission and the pandemics \\
\hline CXCR4 & CXCL12 & $\mathrm{X} 4$ & $\begin{array}{l}\text { Rarely }(<5 \%) \text { observed in advanced infection by subtype B virus, highly cytopathic } \\
\text { in vitro }\end{array}$ \\
\hline CCR5, CXCR4 & & R5X4 & $\begin{array}{l}\text { "dualtropic" viruses, accounting for ca. } 45 \% \text { of subtype B advanced infections; they } \\
\text { can be either mixtures of individual R5 and X4 strains or viruses capable of ex- } \\
\text { ploiting both receptors for gaining entry into target cells }\end{array}$ \\
\hline CCR2, CCR3, CCR5 & & R2R3R5 & "multitropic" viruses, rarely observed \\
\hline
\end{tabular}

This new and definitive classification of HIV phenotypes has allowed a novel understanding of the virus distribution worldwide as well as of the dynamics underlying viral transmission. Most infections at the global scale are caused by CCR5-dependent (R5) HIV-1 whereas CXCR4 is limited for the most part to subtype B strains (dominant in the Western world) and it is very rare in Sub-Saharan Africa or South East Asia, where the epidemics is most rampant [30]. At the interpersonal level, as mentioned, the infectious process is almost invariantly caused by an R5 HIV-1 extremely homogeneous for sequence composition (monophyletic virus) even when the person transmitting the infection harbors a CXCR4-dependent virus as a major variant. An alternative view, however suffering of limited experimental evidence, is that both CXCR4- and CCR5-using HIV-1 variants are transmitted but the former is contained while the latter replicates [31]. After the initial infection, the virus accumulates progressively mutations by the converging effects of the RT enzyme (lacking proof reading capacity, unlike eukaryotic polymerases) and of the host immune response selecting escape viral variants. As a result, in the case of subtype B infection, a "switch" to CXCR4 use occurs in ca. $50 \%$ of the cases and, as mentioned, is 
associated with a more rapid deterioration of the immune system and faster progression to AIDS [32]. When analyzed in greater detail, the "co-receptor switch" in most cases is actually an extension of co-receptor use from CCR5 only to CCR5 and CXCR4 (so called R5X4 dualtropic viruses). Only in rare cases $(<5 \%)$ a true "switch" occurs (from R5 to X4 viruses) [33]. Dualtropic viruses encompass those with gp120 Env molecules capable of engaging both CCR5 and CXCR4 ("truly dualtropic" isolates or strains) or mixtures of R5 and X4 viruses that, together, confer the dualtropic phenotype. Sophisticated automated programs run by companies analyze thousand of PCR-sequences amplified from the plasma (or other body fluids) of infected individuals searching for molecular signatures of either CCR5 or CXCR4 use in order to guide the physician in deciding whether a CCR5 antagonist should or should not be administered to infected individuals as part of a cART cocktail [34].

\section{Correlates of CXCR4 use by HIV}

Why does HIV expands or switches its use of entry co-receptor (while maintaining the requirement for CD4 engagement)? This evolutionary related question does not have a simple answer. Structurally, CCR5 (the main entry co-receptor) is more similar to CCR2 than to CXCR4; however, CCR2 can only occasionally utilized as entry co-receptor and always in association with CCR5 [35]. Looking at the "world map" of co-receptor use, it strikes that CXCR4 use overlaps with the map of the Western world (North America, Europe, Australia) that is also superimposable to that of allergic diseases [36]. Is there a potential, at least partial explanation, for CXCR4 use? Indeed, the hypothesis that a CD4 ${ }^{+} \mathrm{T}$ helper type 2 (Th2) bias could be detrimental for the natural course of HIV disease was early proposed by Mario Clerici and Gene Shearer $(\mathrm{NIH})$, based on the observation that "seronegative" HIV exposed by uninfected individuals (ESN) showed evidence of Th1-dependent immune responses to the virus. This contrasted with the observation that most infected individuals showed a "useless" antibody $(\mathrm{Ab})$ response not capable of preventing the infection [37]. Although this hypothesis was not entirely confirmed by other experimental evidence, individuals with a Th2-bias (such as those with allergies) showed a more aggressive course of HIV disease once infected [38].

Since the key cytokines for developing a Th2 immune response are interleukin-4 (IL4) and IL-13 it is interesting to ask whether these cytokines can affect virus replication and CXCR4 vs. CCR5 use. IL-4 was in fact shown to upregulate CXCR4 expression and, indeed, different studies have proposed a correlation between this effect and the more frequent use of CXCR4 by the infecting virus [39-41].

Curiously, another correlate of CXCR4 use by HIV is the genetic mutation known as CCR2-64I [42]. This silent mutation is in linkage disequilibrium with the CCR5-59653T mutation of the CCR5 promoter [43] leading to decreased expression of CCR5, at least according to some studies [44], although not to others [45]. However, whether the differential use of HIV entry co-receptors is explained by their levels of expression on the surface of $\mathrm{CD}^{+}{ }^{+}$immune cells is debated. Alternatively, or complementarily, engagement of CCR5 and CXCR4, in addition to serve as port of entry for the virus, might lead to differential signaling cascades that contribute to the successful or unsuccessful completion of the infection and further spreading to neighbor cells. Evidence supporting these concepts have been published by several groups, including us, and will be further discussed.

\section{Post-entry advantages or disadvantages of CCR5 vs. CXCR4 co-receptor use}

The elegant studies discovering the chemokine receptor paradigm for HIV entry were mostly conducted using non human cells transfected with different plasmids expressing human chemokine receptors, followed by either binding and/or fusion assays. This has led to the concept that chemokine receptor signaling was not required for accomplishing these early steps of HIV infection (i.e., attachment, binding and membrane fusion) [46]. However, when the infectious process was analyzed in more comprehensive assays differences emerged as consequences of CCR5 vs. CXCR4 use. Likely the first substantial evidence was that CCR5 engagement induced calcium fluxes more robustly than CXCR4 $[47,48]$; of note, calcium fluxes had been previously demonstrated to upregulate the capacity of HIV to replicate in different cell types $[49,50]$. We early observed that sub-optimally activated cord blood cells, either polarized or not towards a Th1 or Th2 phenotype, maintained for several days in IL-2 enriched medium allowed the replication of R5, but not X4 viruses in spite of comparable levels of expression of CCR5 and CXCR4 [51]. A more in depth analysis of this phenomenon revealed that both viruses infected the cells with comparable efficiency (i.e. there was no block in viral entry for $\mathrm{X} 4$ viruses), but R5 viruses showed an approximately 100-fold higher efficiency in spreading after 2-3 days of culture [51]. We refined these observation using dualtropic R5X4 viruses in the same model system; these viruses, characterized by the capacity of using both CCR5 and CXCR4 as entry co-receptors, could replicate effi- 
ciently replicate in Th2 and Th0 cells, but were restricted in Th1 cells [52].

Thus, HIV gp120 Env engagement of CD4 and CCR5 or CXCR4 may lead to downstream effects associated to an at least partially different signaling cascade that could influence the capacity of HIV to spread from the initially seeded cells. Quite surprisingly, we reproduced the same phenotype of R5 permissiveness and $\mathrm{X} 4$ restriction ten years later in a different model system, i.e. children's primary $\mathrm{CD}^{+} \mathrm{T}$ cells cultivated on feeder cells [53]. This experimental model was specifically conceived for growing ex vivo leukocytes from children with primary immunodeficiencies, such as adenosine deaminase deficiency severe combined immunodeficiency (ADA-SCID) [54]. $\mathrm{CD}^{+}{ }^{+} \mathrm{T}$ cells were isolated from either healthy children or children with ADA-SCID after stimulation and culture for a few days on feeder cells and were then maintained in medium enriched with IL-2 for several days before infection. Surprisingly enough, the cells from both healthy and ADA-SCID children showed a skewed capacity of supporting R5 (which was lower in ADA-SCID children before gene therapy), but not $\mathrm{X} 4$ virus replication. In contrast, adults' $\mathrm{CD}^{+} \mathrm{T}$ cells cultivated with the same protocol were equally infected productively by both $\mathrm{R} 5$ and $\mathrm{X} 4 \mathrm{vi}$ ruses. Of interest, gene therapy correction of the ADA-SCID defect resulted in a greater capacity of children' cells to support R5, but not X4 infection [53].

Thus, either cord blood derived $\mathrm{CD}^{+} \mathrm{T}$ cells or peripheral blood $\mathrm{CD}^{+} \mathrm{T}$ cells isolated from young children seem to have an inherent bias for better supporting viruses using CCR5 rather than CXCR4, at least in certain in vitro models of infection. Whether this phenotype can account for the superior capacity of R5 viruses to be efficiently transmitted from infected mothers to their children in comparison to CXCR4-using strains (including both $\mathrm{X} 4$ and R5X4 viruses) is unclear.

Another correlate of successful HIV transmission and infection of $\mathrm{CD}^{+}$target cells that partially over- laps with the differential use of CCR5 and CXCR4 by the virus is its capacity to bind the $\alpha 4 \beta 7$ integrin on the surface of target cells. As mentioned, this molecule is more accessible for the spikes of the incoming virions than CD4 and it is likely that is the first contact molecule between the virus and the cell. Binding to $\alpha 4 \beta 7$ requires the tripeptide motif Leu-Asp-Val sequence present in the V2 loop of gp120 Env [5], a region that has recently gained substantial attention after the first partially successful trial of preventive vaccination, the RV144 Thai trial [55-57]. Viruses bearing such a domain are frequently found as seed viruses being transmitted among individuals [58], although other investigators have not recently confirmed this finding [59].

\section{CXCR4 antagonists. Will they play a role in prevention and therapy of HIV-1 in- fection?}

As mentioned, AMD3100 was the first molecule originally developed as HIV entry inhibitor targeting a host rather than a viral molecule [60]. Its use in HIV infected individuals was, however, rapidly abandoned for unexpected cardiac toxicity [14]. Of interest is the fact that AMD3100 has found a "second life" as mobilizer of extracellular CXCL12 in the context of bone marrow transplantation protocols [61]. Other antagonists or inhibitors of CXCR4 are currently in development, but the real question is whether their use will play an important role or not in the fight to HIV infection. Several reasons of skepticism have been discussed in the article and are summarized in Table 2. Several aspects of HIV immunopathogenesis remains to be clarified and the possibility to develop CXCR4 inhibitors that prevent or limit the capacity of HIV-1 to propagate should remain an important goal to be achieved, likely in combination with CCR5 and/or CD4 antagonists, particularly for patients infected with subtype $B$ viruses and in advanced phase of disease.

Table 2. Findings against a crucial role of CXCR4 as a relevant target for anti-HIV drug development.

\begin{tabular}{|c|c|c|}
\hline Key aspect & Observation & References \\
\hline $\begin{array}{l}\text { HIV transmission, } \\
\text { early viral spreading }\end{array}$ & almost exclusively accounted for by R5 viruses & [63] \\
\hline HIV evolution & $\begin{array}{l}\text { CXCR4 use occurs only in } 50 \% \text { of individuals infected with subtype B virus; almost irrelevant for } \\
\text { other viral subtypes }\end{array}$ & {$[4]$} \\
\hline Spectrum of target cells & X4 viruses do not replicate efficiently in primary macrophages or dendritic cells & [64] \\
\hline Response to cART & $\begin{array}{l}\text { Reported more rapid disappearance of CXCR4-using strains than of R5 viruses due to immunological } \\
\text { reconstitution }\end{array}$ & {$[65]$} \\
\hline
\end{tabular}




\section{Conclusions}

As a lentivirus, HIV-1 has a "natural" propensity to infect cells of the mononuclear phagocytic lineage [62]. In addition, the selection of CD4 as its primary receptor has expanded its cell tropism to a significant subset of $\mathrm{T}$ lymphocytes and likely conferred its unique capacity to cause a profound immunological deficiency. The requirement of a second receptor for infecting its target cells, and the "choice" of a chemokine receptor for this task, has added novel immunopathological consequences to HIV infection. Several mysteries remain on the selection of CCR5 as its primary, and fundamental, entry co-receptor as well as on the choice of CXCR4 as "spared tire" receptor, yet playing a significant role in terms of disease acceleration. The puzzling role of CXCR4 can be summarized, in our view, as follows: on the one hand, CXCR4 use coincides with a superior aggressiveness of the virus both in vitro and in vivo, as above discussed. However, the evolution has favored CCR5 as main entry coreceptor. One of several potential interpretations is that the virus prefers a more subtle, smoldering strategy to colonize the infected individuals, rather than destroying efficiently his $\mathrm{CD}^{+}{ }^{+} \mathrm{T}$ lymphocytes. An opposite hypothesis discussed above is that CCR5 usage confers a superior capacity to the virus to replicate in resting or sub-optimally activated cells, while CXCR4-dependent viruses require a more potent cell activation, perhaps resulting from chronic inflammation, and, in vivo, an already immunologically deficient host in order to spread efficiently. Of course, other hypotheses could be formulated and experimentally explored.

Nonetheless, the development of specific antagonists, or inhibitors, of CCR5 and CXCR4 will likely shed more light on the natural history of HIV disease and, at the same time, provide new tools and perhaps drugs of use in other human diseases, as exemplified by the evolution of CXCR4-antagonist AMD3100.

\section{Abbreviations}

Ab: antibody; ADA-SCID: adenosine deaminase deficiency severe combined immunodeficiency; AIDS: acquired immunodeficiency syndrome (AIDS); CAF: CD8 non-lytic antiviral factor; cART: combination antiretroviral therapy; DC: dendritic cells; DC-SIGN: dendritic cell-specific intercellular adhesion molecule-3-grabbing non-integrin; Env: envelope; HIV: human immunodeficiency virus; ICAM: intercellular adhesion molecules; IL: interleukin; LFA-1: leukocyte functional antigen 1; mDC: myeloid dendritic cells; MIP: macrophage inflammatory protein; NSI: non-syncytium inducing; RANTES: regulated upon activation normal $\mathrm{T}$ cell expressed and secreted; SDF-1 $\alpha$ : stromal cell derived factor- $1 \alpha$; SI: Syncytium inducing; Th: T helper.

\section{Acknowledgments}

This study was partially supported by the Regione Lombardia (SAL-70 (Progetti di Cooperazione Scientifica e tecnologica to GP), by CARIPLO Foundation Grant 2008-2230 (to GP) and by the Italian Ministry of Health Grant Program of AIDS Research 2009- 2010 (to GP and EV).

\section{Competing interest}

The authors declare that no competing interests exist.

\section{References}

1. Barre-Sinoussi F, Chermann JC, Rey F, Nugeyre MT, Chamaret S, Gruest $\mathrm{J}$, et al. Isolation of a T-lymphotropic retrovirus from a patient at risk for acquired immune deficiency syndrome (AIDS). Science. 1983; 220: 868-71.

2. Gallo RC, Salahuddin SZ, Popovic M, Shearer GM, Kaplan M, Haynes $\mathrm{BF}$, et al. Frequent detection and isolation of cytopathic retroviruses (HTLV-III) from patients with AIDS and at risk for AIDS. Science. 1984; 224: 500-3.

3. De Cock KM, Jaffe HW and Curran JW. Reflections on 30 years of AIDS. Emerg Infect Dis. 2011; 17: 1044-8. doi:10.3201/eid/1706.100184.

4. Cicala C, Arthos J and Fauci AS. HIV-1 envelope, integrins and co-receptor use in mucosal transmission of HIV. J Transl Med. 2011; 9 Suppl 1: S2. doi:10.1186/1479-5876-9-S1-S2.

5. Arthos J, Cicala C, Martinelli E, Macleod K, Van Ryk D, Wei D, et al. HIV-1 envelope protein binds to and signals through integrin alpha4beta7, the gut mucosal homing receptor for peripheral T cells. Nat Immunol. 2008; 9: 301-9. doi:10.1038/ni1566.

6. Geijtenbeek TB, Kwon DS, Torensma R, van Vliet SJ, van Duijnhoven GC, Middel J, et al. DC-SIGN, a dendritic cell-specific HIV-1-binding protein that enhances trans-infection of T cells. Cell. 2000; 100: 587-97. doi:S0092-8674(00)80694-7 [pii].

7. Geijtenbeek TB, Torensma R, van Vliet SJ, van Duijnhoven GC, Adema GJ, van Kooyk Y, et al. Identification of DC-SIGN, a novel dendritic cell-specific ICAM-3 receptor that supports primary immune responses. Cell. 2000; 100: 575-85. doi:S0092-8674(00)80693-5 [pii].

8. Soilleux EJ, Morris LS, Leslie G, Chehimi J, Luo Q, Levroney E, et al. Constitutive and induced expression of DC-SIGN on dendritic cell and macrophage subpopulations in situ and in vitro. J Leukoc Biol. 2002; 71: 445-57.

9. Cassol E, Cassetta L, Rizzi C, Gabuzda D, Alfano M and Poli G. Dendritic Cell-Specific ICAM-3 Grabbing Nonintegrin mediates HIV-1 Infection of and Transmission by M2a-Polarized Macrophages In Vitro. Aids. 2012; in press.

10. Turville S, Wilkinson J, Cameron P, Dable J and Cunningham AL. The role of dendritic cell C-type lectin receptors in HIV pathogenesis. Journal of leukocyte biology. 2003; 74: 710-8. doi:10.1189/jlb.0503208.

11. Dalgleish AG, Beverley PC, Clapham PR, Crawford DH, Greaves MF and Weiss RA. The CD4 (T4) antigen is an essential component of the receptor for the AIDS retrovirus. Nature. 1984; 312: 763-7.

12. Deeks SG, Autran B, Berkhout B, Benkirane M, Cairns S, Chomont N, et al. Towards an HIV cure: a global scientific strategy. Nature reviews Immunology. 2012; 12: 607-14. doi:10.1038/nri3262.

13. Lazzarin A, Clotet B, Cooper D, Reynes J, Arasteh K, Nelson M, et al. Efficacy of enfuvirtide in patients infected with drug-resistant HIV-1 in Europe and Australia. N Engl J Med. 2003; 348: 2186-95.

14. De Clercq E. The bicyclam AMD3100 story. Nat Rev Drug Discov. 2003; 2: 581-7. doi:10.1038/nrd1134.

15. Bowen DL, Lane HC and Fauci AS. Immunopathogenesis of the acquired immunodeficiency syndrome. Ann Intern Med. 1985; 103: 704-9.

16. Lores P, Boucher V, Mackay C, Pla M, Von Boehmer H, Jami J, et al. Expression of human CD4 in transgenic mice does not confer sensitivity 
to human immunodeficiency virus infection. AIDS Res Hum Retroviruses. 1992; 8: 2063-71.

17. Feng Y, Broder CC, Kennedy PE and Berger EA. HIV-1 entry cofactor: functional cDNA cloning of a seven-transmembrane, $G$ protein-coupled receptor [see comments]. Science. 1996; 272: 872-7.

18. Aiuti A, Webb IJ, Bleul C, Springer T and Gutierrez-Ramos JC. The chemokine SDF-1 is a chemoattractant for human CD34+ hematopoietic progenitor cells and provides a new mechanism to explain the mobilization of CD34+ progenitors to peripheral blood. J Exp Med. 1997; 185: 111-20.

19. Gruters RA, Terpstra FG, De Goede RE, Mulder JW, De Wolf F, Schellekens PT, et al. Immunological and virological markers in individuals progressing from seroconversion to AIDS. Aids. 1991; 5: 837-44.

20. Schuitemaker H, Kootstra NA, de Goede RE, de Wolf F, Miedema F and Tersmette M. Monocytotropic human immunodeficiency virus type 1 (HIV-1) variants detectable in all stages of HIV-1 infection lack T-cell line tropism and syncytium-inducing ability in primary T-cell culture. J Virol. 1991; 65: 356-63.

21. Bjorndal A, Deng H, Jansson M, Fiore JR, Colognesi C, Karlsson A, et al. Coreceptor usage of primary human immunodeficiency virus type 1 isolates varies according to biological phenotype. J Virol. 1997; 71: 7478-87.

22. Koot M, Vos AH, Keet RP, de Goede RE, Dercksen MW, Terpstra FG, et al. HIV-1 biological phenotype in long-term infected individuals evaluated with an MT-2 cocultivation assay. Aids. 1992; 6: 49-54.

23. Moore JP. Coreceptors: implications for HIV pathogenesis and therapy. Science. 1997; 276: 51-2.

24. Cocchi F, DeVico AL, Garzino-Demo A, Arya SK, Gallo RC and Lusso P. Identification of RANTES, MIP-1 alpha, and MIP-1 beta as the major HIV- suppressive factors produced by CD8+ T cells [see comments]. Science. 1995; 270: 1811-5.

25. Walker CM, Moody DJ, Stites DP and Levy JA. CD8+ lymphocytes can control HIV infection in vitro by suppressing virus replication. Science. 1986; 234: 1563-6.

26. Choe H, Farzan M, Sun Y, Sullivan N, Rollins B, Ponath PD, et al. The beta-chemokine receptors CCR3 and CCR5 facilitate infection by primary HIV-1 isolates. Cell. 1996; 85: 1135-48.

27. He J, Chen Y, Farzan M, Choe H, Ohagen A, Gartner S, et al. CCR3 and CCR5 are co-receptors for HIV-1 infection of microglia. Nature. 1997; 385: 645-9.

28. Aasa-Chapman MM, Seymour CR, Williams I and McKnight A. Novel envelope determinants for CCR3 use by human immunodeficiency virus. J Virol. 2006; 80: 10884-9. doi:80/21/10884 [pii]10.1128/JVI.01030-06.

29. Berger EA, Doms RW, Fenyo EM, Korber BT, Littman DR, Moore JP, et al. A new classification for HIV-1 [letter]. Nature. 1998; 391: 240.

30. Azim T, Saidel TJ and Brown T. Essential elements of strategic information systems to guide focused HIV responses in south and south-east Asia. Aids. 2010; 24 Suppl 3: S54-61. doi:10.1097/01.aids.0000390090.68306.8a.

31. Margolis L and Shattock R. Selective transmission of CCR5-utilizing HIV-1: the 'gatekeeper' problem resolved? Nat Rev Microbiol. 2006; 4: 312-7.

32. Koot M, Keet IP, Vos AH, de Goede RE, Roos MT, Coutinho RA, et al. Prognostic value of HIV-1 syncytium-inducing phenotype for rate of CD4+ cell depletion and progression to AIDS [see comments]. Ann Intern Med. 1993; 118: 681-8.

33. Low AJ, Swenson LC and Harrigan PR. HIV coreceptor phenotyping in the clinical setting. AIDS Rev. 2008; 10: 143-51.

34. Skrabal K, Low AJ, Dong W, Sing T, Cheung PK, Mammano F, et al. Determining human immunodeficiency virus coreceptor use in a clinical setting: degree of correlation between two phenotypic assays and a bioinformatic model. J Clin Microbiol. 2007; 45: 279-84. doi:10.1128/JCM.01118-06.

35. Penton-Rol G, Cota M, Polentarutti N, Luini W, Bernasconi S, Borsatti A, et al. Up-regulation of CCR2 chemokine receptor expression and increased susceptibility to the multitropic HIV strain 89.6 in monocytes exposed to glucocorticoid hormones [In Process Citation]. J Immunol. 1999; 163: 3524-9.

36. Becker $\mathrm{Y}$. The changes in the $\mathrm{T}$ helper 1 (Th1) and $\mathrm{T}$ helper 2 (Th2) cytokine balance during HIV-1 infection are indicative of an allergic response to viral proteins that may be reversed by Th2 cytokine inhibitors and immune response modifiers--a review and hypothesis. Virus Genes. 2004; 28: 5-18. doi:10.1023/B:VIRU.0000012260.32578.72.
37. Clerici M and Shearer GM. A TH1-->TH2 switch is a critical step in the etiology of HIV infection [see comments]. Immunol Today. 1993; 14: 107-11.

38. Del Prete G, Maggi E, Pizzolo G and Romagnani S. Th2 cytokines and HIV infection: a complex and fascinating link. Immunol Today. 1995; 16: 76-80.

39. Jourdan P, Abbal C, Noraz N, Hori T, Uchiyama T, Vendrell JP, et al. IL-4 induces functional cell-surface expression of CXCR4 on human T cells. J Immunol. 1998; 160: 4153-7.

40. Valentin A, Lu W, Rosati M, Schneider R, Albert J, Karlsson A, et al. Dual effect of interleukin 4 on HIV-1 expression: implications for viral phenotypic switch and disease progression. Proc Natl Acad Sci U S A. 1998; 95: 8886-91.

41. Galli G, Annunziato F, Mavilia C, Romagnani P, Cosmi L, Manetti R, et al. Enhanced HIV expression during Th2-oriented responses explained by the opposite regulatory effect of IL-4 and IFN-gamma of fusin/CXCR4. Eur J Immunol. 1998; 28: 3280-90.

42. Vicenzi E, Ghezzi S, Brambilla A, Sheppard HW, Lazzarin A, Poli G, et al. CCR2-64I polymorphism, syncytium-inducing human immunodeficiency virus strains, and disease progression. J Infect Dis. 2000; 182: 1579-80.

43. Martin MP, Dean M, Smith MW, Winkler C, Gerrard B, Michael NL, et al. Genetic acceleration of AIDS progression by a promoter variant of CCR5. Science. 1998; 282: 1907-11.

44. Li C, Lu SC, Hsieh PS, Huang YH, Huang HI, Ying TH, et al. Distribution of human chemokine (C-X3-C) receptor 1 (CX3CR1) gene polymorphisms and haplotypes of the CC chemokine receptor 5 (CCR5) promoter in Chinese people, and the effects of CCR5 haplotypes on CCR5 expression. Int J Immunogenet. 2005; 32: 99-106. doi:10.1111/j.1744-313X.2005.00498.x.

45. Mariani R, Wong S, Mulder LC, Wilkinson DA, Reinhart AL, LaRosa G, et al. CCR2-64I polymorphism is not associated with altered CCR5 expression or coreceptor function. J Virol. 1999; 73: 2450-9.

46. Gosling J, Monteclaro FS, Atchison RE, Arai H, Tsou CL, Goldsmith MA, et al. Molecular uncoupling of $\mathrm{C}-\mathrm{C}$ chemokine receptor 5-induced chemotaxis and signal transduction from HIV-1 coreceptor activity. Proc Natl Acad Sci U S A. 1997; 94: 5061-6.

47. Weissman D, Rabin RL, Arthos J, Rubbert A, Dybul M, Swofford R, et al. Macrophage-tropic HIV and SIV envelope proteins induce a signal through the CCR5 chemokine receptor. Nature. 1997; 389: 981-5.

48. Del Corno M, Liu QH, Schols D, de Clercq E, Gessani S, Freedman BD, et al. HIV-1 gp120 and chemokine activation of Pyk2 and mitogen-activated protein kinases in primary macrophages mediated by calcium-dependent, pertussis toxin-insensitive chemokine receptor signaling. Blood. 2001; 98: 2909-16.

49. Cloyd MW, Lynn WS, Ramsey K and Baron S. Inhibition of human immunodeficiency virus (HIV-1) infection by diphenylhydantoin (dilantin) implicates role of cellular calcium in virus life cycle. Virology. 1989; 173: 581-90.

50. Kinter AL, Poli G, Maury W, Folks TM and Fauci AS. Direct and cytokine-mediated activation of protein kinase $\mathrm{C}$ induces human immunodeficiency virus expression in chronically infected promonocytic cells. J Virol. 1990; 64: 4306-12.

51. Vicenzi E, Bordignon PP, Biswas P, Brambilla A, Bovolenta C, Cota M, et al. Envelope-dependent restriction of human immunodeficiency virus type 1 spreading in CD4(+) T lymphocytes: R5 but not X4 viruses replicate in the absence of T-cell receptor restimulation. J Virol. 1999; 73: 7515-23.

52. Vicenzi E, Panina-Bodignon P, Vallanti G, Di Lucia P and Poli G. Restricted replication of primary HIV-1 isolates using both CCR5 and CXCR4 in Th2 but not in Th1 CD4(+) T cells. J Leukoc Biol. 2002; 72: 913-20.

53. Mariani SA, Brigida I, Kajaste-Rudnitski A, Ghezzi S, Rocchi A, Plebani A, et al. HIV-1 envelope-dependent restriction of CXCR4-using viruses in child but not adult untransformed CD4+ T-lymphocyte lines. Blood. 2012; 119: 2013-23. doi:10.1182/blood-2010-12-325308.

54. Bacchetta R, de Waal Malefijt R, Yssel H, Abrams J, de Vries JE, Spits H, et al. Host-reactive CD4+ and CD8+ T cell clones isolated from a human chimera produce IL-5, IL-2, IFN-gamma and granulocyte/macrophage-colony-stimulating factor but not IL-4. J Immunol. 1990; 144: 902-8.

55. Karasavvas N, Billings E, Rao M, Williams C, Zolla-Pazner S, Bailer RT, et al. The Thai Phase III HIV Type 1 Vaccine Trial (RV144) Regimen Induces Antibodies That Target Conserved Regions Within the V2 Loop of gp120. AIDS Res Hum Retroviruses. 2012. doi:10.1089/aid.2012.0103. 
56. Rolland M, Edlefsen PT, Larsen BB, Tovanabutra S, Sanders-Buell E, Hertz T, et al. Increased HIV-1 vaccine efficacy against viruses with genetic signatures in Env V2. Nature. 2012. doi:10.1038/nature11519.

57. de Souza MS, Ratto-Kim S, Chuenarom W, Schuetz A, Chantakulkij S, Nuntapinit B, et al. The Thai phase III trial (RV144) vaccine regimen induces $\mathrm{T}$ cell responses that preferentially target epitopes within the V2 region of HIV-1 envelope. J Immunol. 2012; 188: 5166-76. doi:10.4049/jimmunol.1102756.

58. Nawaz F, Cicala C, Van Ryk D, Block KE, Jelicic K, McNally JP, et al. The genotype of early-transmitting HIV gp120s promotes alpha (4) beta(7)-reactivity, revealing alpha (4) beta(7) +/CD4+ T cells as key targets in mucosal transmission. PLoS Pathog. 2011; 7: e1001301. doi:10.1371/journal.ppat.1001301.

59. Parrish NF, Wilen CB, Banks LB, Iyer SS, Pfaff JM, Salazar-Gonzalez JF, et al. Transmitted/founder and chronic subtype C HIV-1 use CD4 and CCR5 receptors with equal efficiency and are not inhibited by blocking the integrin alpha4beta7. PLoS Pathog. 2012; 8: e1002686. doi:10.1371/journal.ppat.1002686.

60. De Clercq E. Inhibition of HIV infection by bicyclams, highly potent and specific CXCR4 antagonists. Mol Pharmacol. 2000; 57: 833-9.

61. Larochelle A, Krouse A, Metzger M, Orlic D, Donahue RE, Fricker S, et al. AMD3100 mobilizes hematopoietic stem cells with long-term repopulating capacity in nonhuman primates. Blood. 2006; 107: 3772-8. doi:10.1182/blood-2005-09-3592.

62. Clements JE, Zink MC, Narayan O and Gabuzda DH. Lentivirus infection of macrophages. Immunol Ser. 1994; 60: 589-600.

63. Grivel JC, Shattock RJ and Margolis LB. Selective transmission of R5 HIV-1 variants: where is the gatekeeper? J Transl Med. 2011; 9 Suppl 1: S6. doi:10.1186/1479-5876-9-S1-S6.

64. Loftin LM, Kienzle M, Yi Y and Collman RG. R5X4 HIV-1 coreceptor use in primary target cells: implications for coreceptor entry blocking

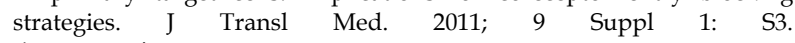
doi:10.1186/1479-5876-9-S1-S3.

65. Verhofstede $C$, Nijhuis $M$ and Vandekerckhove L. Correlation of coreceptor usage and disease progression. Curr Opin HIV AIDS. 2012; 7: 432-9. doi:10.1097/COH.0b013e328356f6f2. 